\title{
A Simple Colorimetric Procedure for Differentiating Anions using Flower Pigments from Anthurium andreanum
}

\author{
MAYNARD O. GALINGANA and VOLTAIRE G. ORGANO* \\ Department of Physical Sciences and Mathematics, College of Arts and Sciences, \\ University of the Philippines, Manila, Philippines. \\ ${ }^{*}$ Corresponding author E-mail: vgorgano@up.edu.ph \\ http://dx.doi.org/10.13005/ojc/320308
}

(Received: April 16, 2016; Accepted: May 25, 2016)

\begin{abstract}
A simple, "green" and colorimetric approach in differentiating various anions is presented. Acidified ethanolic extracts from flowers of Anthurium andreanum undergo color changes in the presence of $\mathrm{HSO}_{4}^{-}, \mathrm{CH}_{3} \mathrm{COO}, \mathrm{C}_{6} \mathrm{H}_{5} \mathrm{COO}, \mathrm{HCO}_{3}, \mathrm{CO}_{3}{ }^{2-}, \mathrm{HPO}_{4}{ }^{2-}$ and $\mathrm{PO}_{4}{ }^{3-}$ anions in aqueous solutions. Anionic acid-base conjugate pairs such as $\mathrm{HCO}_{3}{ }^{-}$and $\mathrm{CO}_{3}{ }^{2-}, \mathrm{HSO}_{4}^{-}$and $\mathrm{SO}_{4}{ }^{2-}$, and phosphates $\mathrm{H}_{2} \mathrm{PO}_{4} ; \mathrm{HPO}_{4}{ }^{2-}$, and $\mathrm{PO}_{4}{ }^{3-}$ can also be discriminated from each other. Visible spectroscopic analysis indicates possible structural changes in pigments due to $\mathrm{pH}$ change of solution as a consequence of the basic property of anions.
\end{abstract}

Keywords: Colorimetric; Anthurium andreanum extracts; anion recognition; flower pigments.

\section{INTRODUCTION}

Interest in anion recognition has grown in recent years. This can be attributed to its significance in biological, chemical and industrial systems. ${ }^{1,2}$ Anion sensors being developed are generally composed of a recognition unit and a signalling unit. ${ }^{3}$ For example, anions can bind to a positive site in the host molecule through electrostatic interaction. Anions can also interact to its receptor via hydrogen bonding containing structural moieties such as amide, ${ }^{4}$ urea, ${ }^{5}$ thiourea,,${ }^{6,7}$ hydroxyl, ${ }^{8}$ sulfonamide,, 90 pyrrole ${ }^{11,12}$ and indole. ${ }^{13,14}$ The interaction between the recognition unit and the anion significantly affects the signalling unit, leading to changes in color, fluorescence and/or electrochemical properties of the chemosensor. ${ }^{3}$ It is believed that anion detection depends on a number of factors, namely, basicity of the anion, geometry and solvent effects. ${ }^{15}$

While these synthetic chemosensors provide good selectivity, such approaches require expensive materials and lengthy procedures for its synthesis. Moreover, anion sensing is usually performed in aprotic solvents because protic solvents can compete with the interaction between 
the receptor and the anion. ${ }^{16}$ The use of these organic solvents however poses serious health and environmental concerns.

On the other hand, natural pigments can be utilized as green alternatives for molecular and ion recognition. Recently, Hartwell ${ }^{17}$ has cited several studies involving the use of plant-based reagents for analyses of metal ions, alcohols, formaldehyde, and $\mathrm{H}_{2} \mathrm{O}_{2}$, among others. Such approaches have been found suitable in teaching chemical analyses, especially in schools with limited financial resources.

The most common among these Naturebased reagents are pigments found in flower extracts. These plant-based reagents have been commonly used as acid-base titration indicators. ${ }^{18-20}$ Other laboratory experiments have used flower pigments to demonstrate basic properties of common household chemicals such as baking soda and ammonia. However, application of flower pigments for anion analysis is unprecedented to the best of our knowledge. This study attempts to differentiate anionic species based on their ability to act as bases in aqueous solution through their response to a flower-based $\mathrm{pH}$ indicator. The method presented here is simple, cheap and environment-friendly.

\section{MATERIALS AND METHODS}

Sodium salts of $\mathrm{NO}_{3}^{-}, \mathrm{SO}_{4}^{2-}, \mathrm{F}, \mathrm{I}, \mathrm{CH}_{3} \mathrm{COO}$ (OAc), $\mathrm{C}_{6} \mathrm{H}_{5} \mathrm{COO}^{-}\left(\mathrm{BzO}^{-}\right), \mathrm{HCO}_{3}^{-}, \mathrm{CO}_{3}^{2-}, \mathrm{H}_{2} \mathrm{PO}_{4}^{-}$, $\mathrm{HPO}_{4}{ }^{2-}$ and $\mathrm{PO}_{4}{ }^{3-}$ and potassium salts of $\mathrm{SCN}$, $\mathrm{HSO}_{4}^{-}, \mathrm{Cl}$ and $\mathrm{Br}$ used in this study were of analytical grade and the solutions were prepared with distilled water.

Fifty grams of flower petals from Anthurium andreanum were washed with distilled water, macerated or soaked in acidified ethanol $(0.1 \% \mathrm{v} / \mathrm{v}$ $\mathrm{HCl}$ ), refrigerated for 1 day and filtered. Qualitative tests were performed to confirm the presence of anthocyanins, according to published procedures. ${ }^{21}$ Two-milliliter aqueous solutions of anion salts, each having a concentration of $0.010 \mathrm{M}$, were prepared in separate vials. One milliliter of the flower extract was added to each vial. A separate vial which only contains the flower extract served as control. The mixtures were then shaken and color changes were noted. The absorption spectra of all mixtures were generated from $700 \mathrm{~nm}$ to $300 \mathrm{~nm}$ through Hitachi U-2900 spectrophotometer. The $\mathrm{pH}$ of the solutions prior to addition of the extract was measured using Hanna Instruments HI 98103 Checker pH meter.

\section{RESULTS AND DISCUSSION}

Several studies have been conducted utilizing pigments from flowers as $\mathrm{pH}$ indicators. ${ }^{22}$ Pigments such as anthocyanins are known to be influenced by changes in $\mathrm{pH}$, producing varied colors from red to blue to yellow. ${ }^{23}$ For example, the red-colored flavyliun cation is the predominant species at $\mathrm{pH} 1$, while the blue quinoidal species predominates at $\mathrm{pH}$ 4. Depending on the $\mathrm{pH}$ of the solution, phenolic hydroxyl groups in the anthocyanin rings are protonated or deprotonated, shifting the equilibrium towards the corresponding anthocyanin form as flavylium cation, quinoidal base, carbinol pseudobase or chalcone. ${ }^{24}$ Colors of the pigments may also vary depending on the substituents and presence of hydroxyl or alkoxy groups on the aromatic rings of anthocyanins. ${ }^{25}$

Anions can act as Arrhenius or BronstedLowry bases which can alter the $\mathrm{pH}$ of a solution or directly deprotonate phenolic groups of pigments, and consequently, change the color of pigments. Thus, anions can be differentiated indirectly from each other according to its base strength $\left(K_{b}\right)$. In this study, flower extracts from Anthurium andreanum have been applied as a source of pigments which can be used as potential reagent for differentiating anions in aqueous solution. Qualitative analysis of the anthurium extract has confirmed the presence of anthocyanins. Previous studies have identified these pigments as glycosylated anthocyanin derivatives such as pelargonidin and cyanidin 3-rutinoside. ${ }^{26}$ These pigments have acidic phenolic groups which can potentially interact with basic anions and cause color changes.

Results show that solutions containing $\mathrm{OAc}, \mathrm{BzO}^{-}, \mathrm{HCO}_{3}^{-}$, and $\mathrm{CO}_{3}{ }^{2-}$ changed color after mixing with anthurium extract (Fig. 1 insert). Color of the pigments changed from maple to brown. It was also observed that at the same concentration, $\mathrm{OAc}^{-}, \mathrm{BzO}^{-}, \mathrm{HCO}_{3}{ }^{-}$and $\mathrm{CO}_{3}{ }^{2-}$ differ from one another through varying intensities of brown color. 


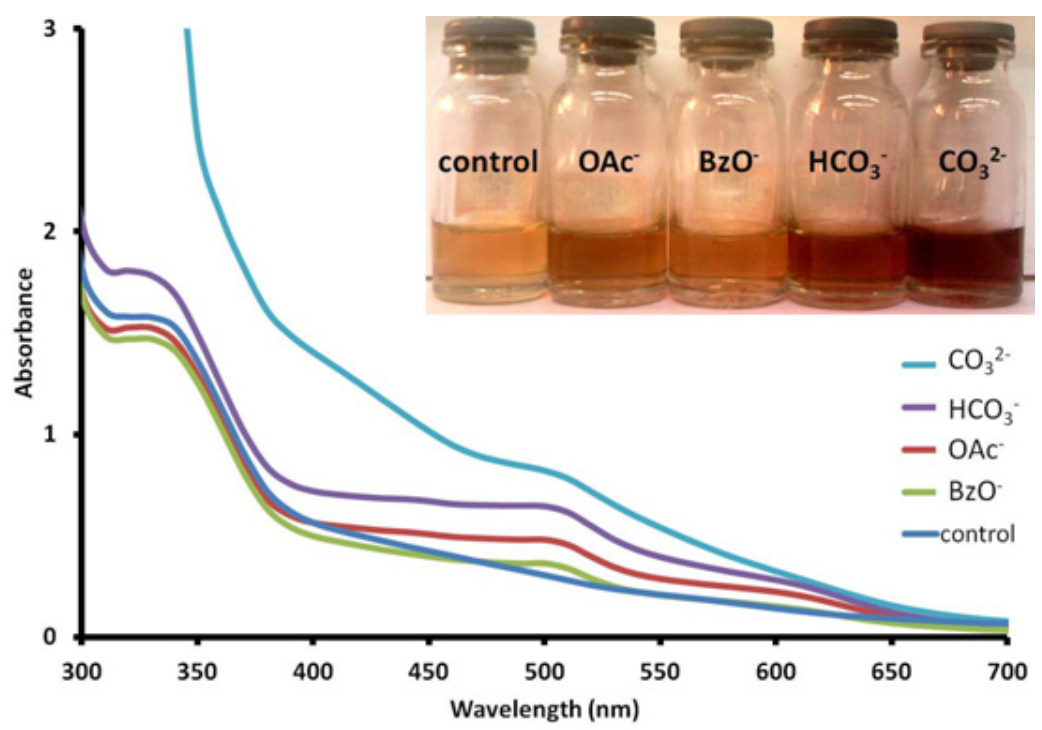

Fig. 1: Absorption spectra of Anthurium flower extracts upon addition of $0.010 \mathrm{M}$ aqueous solutions of $\mathrm{OAc}^{-}, \mathrm{BzO}^{-}, \mathrm{HCO}_{3}^{-}$, and $\mathrm{CO}_{3}{ }^{2-}$ anions. Insert: Visual color changes of solutions containing flower extracts and corresponding anions

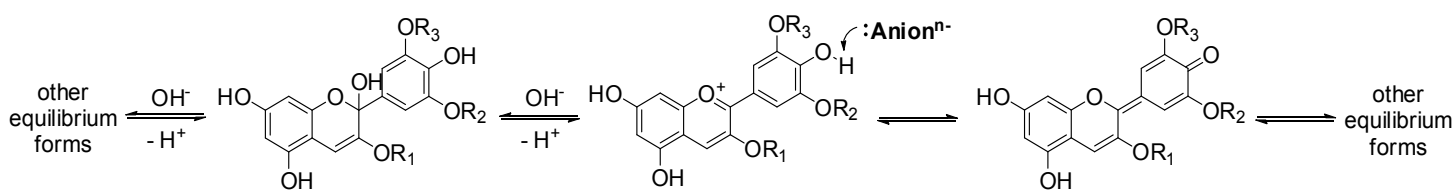

Fig. 2: Proposed interactions between anthurium pigments (anthocyanins) and anions

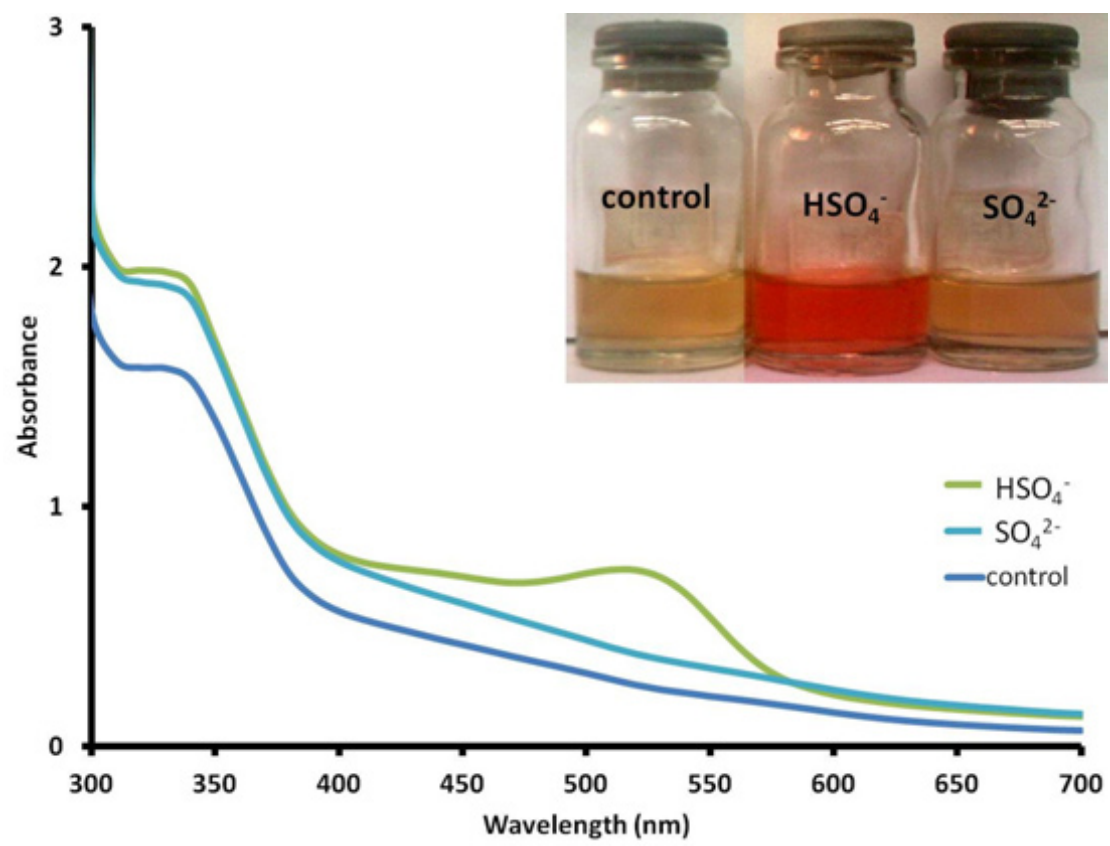

Fig. 3: Absorption spectra of Anthurium flower extracts upon addition of $0.010 \mathrm{M}$ aqueous solutions of $\mathrm{HSO}_{4}^{-}$, and $\mathrm{SO}_{4}{ }^{2-}$ anions. Insert: Visual color changes of solutions containing flower extracts and corresponding anions 
Absorbance spectra of the solutions showed a slight increase in absorbance at $500 \mathrm{~nm}$ for BzOand at $500-600 \mathrm{~nm}$ for OAc' anion compared to the control solution (Fig. 1). Interestingly, the solution treated with $\mathrm{CO}_{3}{ }^{2-}$ exhibited a color change from maple to dark brown compared to its conjugate acid, $\mathrm{HCO}_{3}^{-}$which produced a lighter brown color. Solutions containing $\mathrm{HCO}_{3}^{-}$or $\mathrm{CO}_{3}^{2-}$ exhibited a

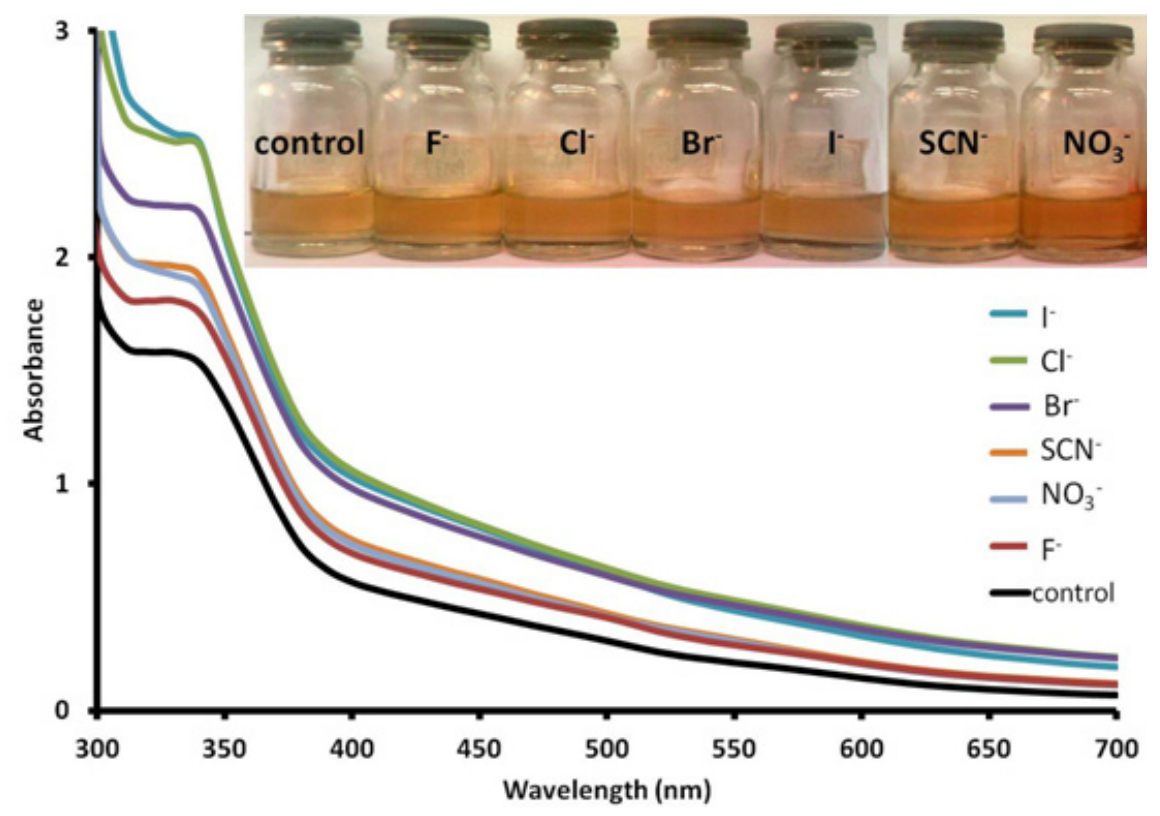

Fig. 4: Absorption spectra of Anthurium flower extracts upon addition of $0.010 \mathrm{M}$ aqueous solutions of $\mathrm{F}^{-}, \mathrm{Cl}^{-}, \mathrm{Br}^{-} \mathrm{I}^{-}, \mathrm{NO}_{3}^{-}$, and $\mathrm{SCN}^{-}$anions. Insert: Visual color changes of solutions containing flower extracts and corresponding anions

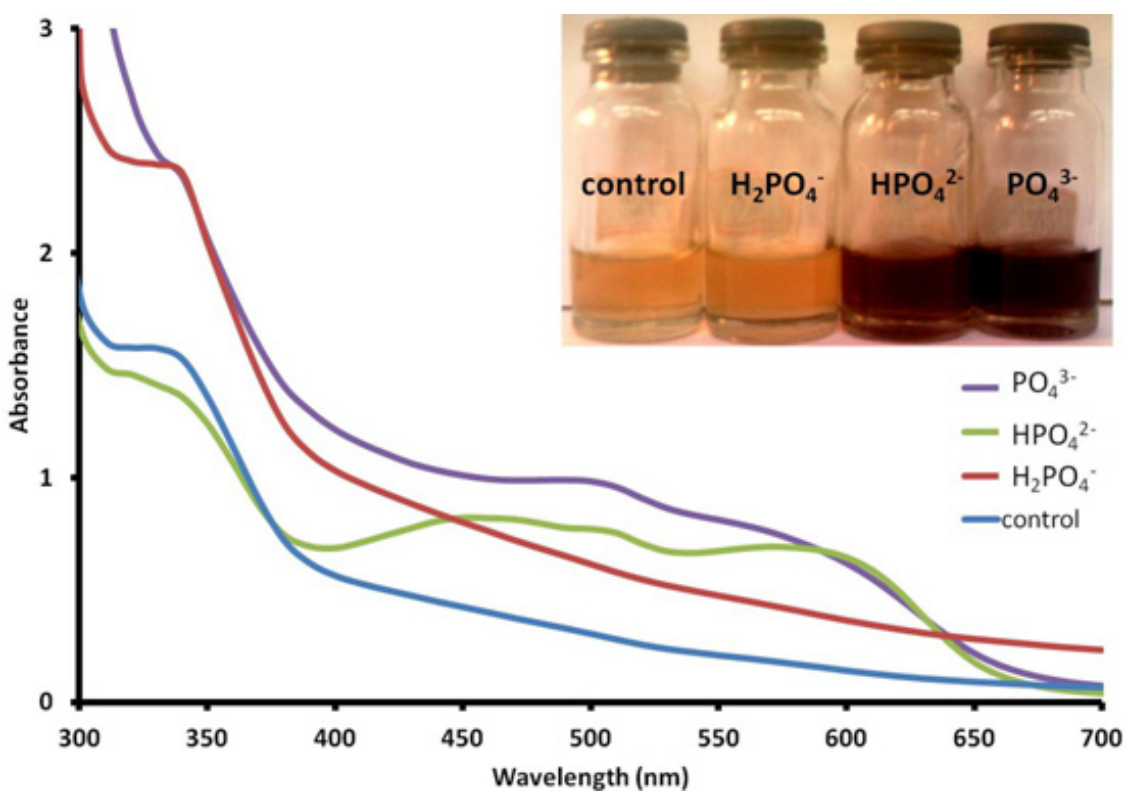

Fig. 5: Absorption spectra of Anthurium flower extracts upon addition of $0.010 \mathrm{M}$ aqueous solutions of $\mathrm{H}_{2} \mathrm{PO}_{4}{ }^{-}, \mathrm{HPO}_{4}{ }^{2-}$, and $\mathrm{PO}_{4}{ }^{3-}$ anions. Insert: Visual color changes of solutions containing flower extracts and corresponding anions 
higher absorbance at $\lambda_{\max }=330 \mathrm{~nm}, 500 \mathrm{~nm}$ and $600 \mathrm{~nm}$ compared to the extract solution and to solutions containing $\mathrm{OAc}^{-}$and $\mathrm{BzO}^{-}$anions. $\mathrm{Narciso}^{27}$ observed a similar increase in absorbance at these wavelengths when the extract is subjected to alkaline $\mathrm{pH}$. It was noted that solutions of anions were found to increase from $\mathrm{pH} 7$ for $\mathrm{BzO}^{-}$and $\mathrm{OAc}^{-}$anions to $\mathrm{pH} 9$ for $\mathrm{HCO}_{3}{ }^{-}$and $\mathrm{pH} 11$ for $\mathrm{CO}_{3}{ }^{2-}$. This change in solution $\mathrm{pH}$ may be responsible for the color change since flower pigments are affected by $\mathrm{pH} .{ }^{24} \mathrm{On}$ the other hand, anions can also interact directly with pigments in the anthurium extract via acid-base reaction (Fig. 2). It has been shown previously ${ }^{28}$ that OAc can provide structural information on several flavonoids by acting as a Bronsted-Lowry base against strongly acidic phenolic hydroxyl groups. Thus, anions such as $\mathrm{BzO}^{-}, \mathrm{HCO}_{3}{ }^{-}$and $\mathrm{CO}_{3}{ }^{2-}$ can also react with anthurium pigments in a similar manner. The observed color change can be correlated to the anion's base strength. According to literature, ${ }^{29}$ the base strength of the anions is arranged in the following order: $\mathrm{BnO}-<\mathrm{OAc}^{-}<\mathrm{HCO}_{3}^{-}<\mathrm{CO}_{3}{ }^{2-}$. This pattern corresponds well with the increasing intensity of brown color and the corresponding increase in absorbance from $300 \mathrm{~nm}$ to $600 \mathrm{~nm}$.

Another interesting result was noted when flower extracts were treated separately with the conjugate pairs, $\mathrm{HSO}_{4}^{-}$and $\mathrm{SO}_{4}{ }^{2-}$. It was observed that $\mathrm{HSO}_{4}$ - was able to change the color of the extract from maple to cherry red. $\mathrm{SO}_{4}{ }^{2-}$ anion, however, did not result in a color change. Absorption spectra of the solution containing $\mathrm{SO}_{4}{ }^{2-}$ showed a slight increase in absorbance compared to the control solution (Fig. 3). This difference however was not significant enough to be detected by the naked eye. On the other hand, formation of an absorption band at $510 \mathrm{~nm}$ exhibited by the $\mathrm{HSO}_{4}^{-}$-containing solution is consistent with the observed color change. It was also noted that similar weak bases such as $\mathrm{F}^{-}, \mathrm{NO}_{3}^{-}, \mathrm{SCN}^{-}, \mathrm{Cl}^{-}, \mathrm{Br}^{-}$ and $\mathrm{l}$ - did not cause a color change of the pigments as shown in Fig. 4. Compared to other oxy-anions such as $\mathrm{HCO}_{3}^{-}, \mathrm{H}_{2} \mathrm{PO}_{4}^{-}$and $\mathrm{HPO}_{4}^{2-}$, only $\mathrm{HSO}_{4}^{-}$has shifted the color of the flower extract to a reddish color. This color change is also produced when the anthurium extract is placed in slightly acidic $\mathrm{pH}^{27}$ It has been noted that the $\mathrm{HSO}_{4}$ - solution has an acidic $\mathrm{pH}$ prior to addition of the flower extract. In contrast, solutions of the halides, $\mathrm{NO}_{3}-\mathrm{SCN}^{-}$and $\mathrm{SO}_{4}{ }^{2-}$ were found to have $\mathrm{pH} 5-6$. Hence, it is possible that $\mathrm{HSO}_{4}^{-}$may have acted as a Bronsted-Lowry acid instead of a base. The absorption band produced at $510 \mathrm{~nm}$ can be attributed to the formation of flavylium cation. ${ }^{30}$ The flavylium cation produces an orange to purple color and exists predominantly at lower $\mathrm{pH}$. Furthermore, $\mathrm{HSO}_{4}^{-}$anion is a relatively stronger acid compared to $\mathrm{HCO}_{3}^{-}, \mathrm{HPO}_{4}^{2-}$ and $\mathrm{H}_{2} \mathrm{PO}_{4}^{-}$. This may account for the selective recognition of $\mathrm{HSO}_{4}^{-}$by anthurium pigments.

Anthurium pigments were also able to distinguish the different ionic phosphate species $\mathrm{PO}_{4}{ }^{3-}, \mathrm{HPO}_{4}{ }^{2-}$ and $\mathrm{H}_{2} \mathrm{PO}_{4}$ - Solution containing $\mathrm{PO}_{4}{ }^{3-}$ changed the pigment color to dark violet while $\mathrm{HPO}_{4}^{2-}$ produced a dark brown solution. On the other hand, $\mathrm{H}_{2} \mathrm{PO}_{4}$ - did not result in a color change with the flower extract. Absorption spectra for solutions treated with various ionic phosphate species are shown in Fig. 5. $\mathrm{H}_{2} \mathrm{PO}_{4}$ - caused an increase in absorbance compared to the extract solution. This however did not result in a color change via visual inspection. On the other hand, a broad band from 460-590 nm, which may be a product of several overlapping bands, was observed for $\mathrm{HPO}_{4}{ }^{2-}$-treated solution. Presence of $\mathrm{PO}_{4}{ }^{3-}$ anions also led to spectral changes similar to that for $\mathrm{HPO}_{4}^{2-}$ but with higher absorbances at shorter wavelengths (below $590 \mathrm{~nm}$ ). Ability of the pigments to distinguish the different ionic phosphate species can also be attributed to the basic properties of these anionic species. Likewise, the $\mathrm{pH}$ of the solution also increased from $\mathrm{pH} 6$ to $\mathrm{pH} 12$ for $\mathrm{H}_{2} \mathrm{PO}_{4}$ - to $\mathrm{PO}_{4}{ }^{3-}$. This corresponds well with the observed color change of the pigment towards basic solution. ${ }^{27}$

\section{CONCLUSION}

This study has shown that pigments in the flowers of Anthurium andreanum can be employed in differentiating anions in aqueous solvent. Anthurium pigments undergo various color changes in the presence of equimolar concentrations of $\mathrm{HSO}_{4}^{-}, \mathrm{OAc}^{-}, \mathrm{BzO}, \mathrm{HCO}_{3}^{-}, \mathrm{CO}_{3}{ }^{2-}, \mathrm{HPO}_{4}{ }^{2-}$ and $\mathrm{PO}_{4}^{3-}$ anions. The pigments are particularly useful in differentiating anion acid-base conjugate pairs like $\mathrm{HSO}_{4}{ }^{-} / \mathrm{SO}_{4}{ }^{2-}, \mathrm{HCO}_{3}{ }^{-} / \mathrm{CO}_{3}{ }^{2-}$, and inorganic phosphate species $\mathrm{H}_{2} \mathrm{PO}_{4}^{-}, \mathrm{HPO}_{4}^{2-}$ and $\mathrm{PO}_{4}^{3-}$. The study also demonstrates the general utility of natural pigments as reagents for colorimetric anion recognition based on its basic properties. This approach is 
simple, cheap, and applies principles of Green Chemistry. The method presented here also allows for naked-eye, colorimetric qualitative analysis of various anions, and therefore does not require any sophisticated equipment. Hence, this approach can be used as a simple experiment in any educational setting to teach chemistry concepts such as acidbase reactions, base strength, ionic equilibrium and chemical analysis of anions.

\section{REFERENCES}

1. Gale, P. A.; Busschaert, N.; Haynes, C. J. E.; Karagiannidis, L. E.; Kirby, I. L. Chem. Soc. Rev. 2014, 43, 205-241.

2. Gale, P. A. Chem. Soc. Rev. 2010, 39, 37463771.

3. Martínez-Máñez, R.; Sancenón, F. Chem. Rev. 2003, 103, 4419-4476.

4. Brooks, S. J.; Gale, P. A.; Light, M. E. Chem. Commun. 2006, 4344-4346.

5. Amendola, V.; Fabbrizzi, L.; Mosca, L. Chem. Soc. Rev. 2010, 39, 3889-3915.

6. Misra, A.; Shahid, M.; Dwivedi, P. Talanta 2009, 80, 532-538.

7. Nie, L.; Li, Z.; Han, J.; Zhang, X.; Yang, R.; Liu, W.-X.; Wu, F.-Y.; Xie, J.-W.; Zhao, Y.-F.; Jiang, Y.-B. J. Org. Chem. 2004, 69, 6449-6454.

8. Hijji, Y. M.; Barare, B.; Zhang, Y. Sensors Actuators, B Chem. 2012, 169, 106-112.

9. Fuentes de Arriba, Á. L.; Turiel, M. G.; Simón, L.; Sanz, F.; Boyero, J. F.; Muñiz, F. M.; Morán, J. R.; Alcázar, V. Org. Biomol. Chem. 2011, 9, 8321-8327.

10. Shang, X.-F.; Lin, H.; Lin, H.-K. J. Fluor. Chem. 2007, 128, 530-534.

11. Zhang, Y.; Yin, Z.; Li, Z.; He, J.; Cheng, J. P. Tetrahedron 2007, 63, 7560-7564.

12. Cho, W.-S.; Sessler, J. L. In Functional Synthetic Receptors; Wiley-VCH Verlag GmbH \& Co. KGaA, 2005; pp. 165-256.

13. Lv, Y.; Guo, Y.; Xu, J.; Shao, S. J. Fluor. Chem. 2011, 132, 973-977.

14. Gale, P. A. Chem. Commun. (Camb). 2008, 4525-4540.

15. Beer, P. D.; Gale, P. A. Angew. Chem. Int. Ed. Engl. 2001, 40, 486-516.

16. Kubik, S. Chem. Soc. Rev. 2010, 39, 36483663.
17. Kradtap Hartwell, S. Chem. Educ. Res. Pract 2012, 13, 135

18. Gupta, P.; Jain, P.; Kumar Jain, P. J. Chem. Pharm. Res. 2012, 4, 4957-4960.

19. Vankar, P. S.; Bajpai, D. Electron. J. Environ. Agric. Food Chem. 2010, 9, 875-884.

20. Gupta, P.; Jain, P.; Jain, P. K. Int. J. Pharm. Technol. 2012, 4, 5038-5045.

21. Nielson, L. R.; Harley, S. M. J. Biol. Educ. 1996, 30, 88.

22. Mohd, P.; Khan, A.; Farooqui, M. J. Adv. Sci. Res. 2011, 2, 20-27.

23. Castaneda-Ovando, A., Pacheco-Hernandez, M. D., Paez-Hernandez, M. A., Rodriguez, J. A., Galan-Vidal, C. A. Food Chem. 2009, 113, 859-871.

24. Wrolstad, R. E.; Durst, R. W.; Lee, J. Trends Food Sci. Technol. 2005, 16, 423-428.

25. Gonnet, J.-F. Colour effects of co-pigmentation of anthocyanins revisited-1. A colorimetric definition using the CIELAB scale. Food Chemistry, 1998, 63, 409-415.

26. Li, C.; Yang, G.; Huang, S.; Lü, D.; Wang, C.; Chen, J.; Yin, J. J. Hortic. Sci. Biotechnol. 2013, 88, 208-215.

27. Narciso, K. S. M. pKa Determination of Free and Immobilized Acid-Base Indicators Extracted from Agpanthus praecox, Anthurium andreanum, and Dianthus caryophyllus, University of the Philippines, Manila, 2012.

28. Horowitz, R. M.; Jurd, L. J. Org. Chem. 1961, 26, 2446-2449.

29. Perrin, D. D. Pure Appl. Chem. 1969, 20, 133-236.

30. Giusti, M. M.; Wrolstad, R. E. Curr. Protoc. Food Anal. Chem. 2001, 1-13. 